\title{
Case report: Acute Localized Exanthematous Pustulosis Following mRNA-1273 SARS-CoV-2 Vaccination
}

\author{
Peter A. Young, MPAS*, Jessica B. Chan, MD, FASCP, Michael W. Su, MD, PhD, FAAD
}

The Permanente Medical Group, Department of Dermatology, Sacramento, CA, USA.

*Corresponding Author: Peter A. Young, the Permanente Medical Group, Department of Dermatology, Sacramento, CA, USA.

Received Date: October 01, 2021 | Accepted Date: October 14, 2021 | Published Date: October 20, 2021

Citation: Peter A Young, Jessica B Chan, Michael W Su. (2021). Case report: Acute Localized Exanthematous Pustulosis Following mRNA-1273 SARS-CoV-2 Vaccination. International Journal of Clinical Case Reports and Reviews. 8(5); DOI:10.31579/2690-4861/180

Copyright: () 2021 Peter A Young, This is an open-access article distributed under the terms of the Creative Commons Attribution License, which permits unrestricted use, distribution, and reproduction in any medium, provided the original author and source are credited.

\section{Abstract \\ Acute localized exanthematous pustulosis (ALEP) is a rare subtype of acute generalized exanthematous pustulosis (AGEP) with identical histologic findings. It results from a T-cell related neutrophilic inflammatory response and is characterized by monomorphic sterile pustules confined to the face, neck, or chest. Two cases of similar facial pustular eruptions in association with the messenger RNA-1273 SARS-CoV-2 vaccine have been reported, both in males of lighter skin over 50 years old. To highlight this rare reaction and its clinical appearance in patients of pigment-rich skin, we report the case of a young adult female with ALEP following injection of the RNA-1273 SARS-CoV-2 vaccine. \\ Keywords: acute localized exanthematous pustulosis; ALEP; COVID-19; vaccine reaction; mRNA-1273 SARS-CoV-2 vaccine}

\section{Introduction}

Acute generalized exanthematous pustulosis (AGEP) is a severe cutaneous reaction pattern characterized by fever, neutrophilia, and sterile pustules on an erythematous background. Acute localized exanthematous pustulosis (ALEP) is a rare subtype of AGEP with identical histologic findings, characterized by monomorphic sterile pustules confined to the face, neck, or chest. Like AGEP, reported cases of ALEP are mostly female, and resolution rapidly follows cessation of the culprit medication [1].

Pathophysiologically, ALEP results from a T-cell related neutrophilic inflammatory response [1]. Drug-specific cytotoxic T-cells and cytotoxic proteins induce apoptosis of keratinocytes, creating subcorneal vesicles. These T-cells and subsequently activated bystander and inflammatory cells release cytokines and chemokines which precipitate neutrophilic inflammation and pustule formation [2]. The differential diagnosis of ALEP includes folliculitis, pustular contact dermatitis, varicella, Kaposi varicelliform eruption, bullous impetigo, pustular erythema multiforme, rosacea fulminans, and others. These are differentiated from ALEP based on history, appearance, skin cultures, and histology [1].

Associations have been reported for ALEP with NSAIDs [1], medroxyprogesterone [3], and vaccinations [4]. Two cases of facial pustular neutrophilic eruption have been described in association with the messenger RNA-1273 SARS-CoV-2 vaccine (one after an initial dose, the other after the second dose only). Both cases were males over 50 years old with lighter skin who described symptom onset within 24 hours of vaccination, with steady worsening over several days. One of these cases was treated successfully with topical corticosteroids [5].

\section{Presentation}

A 25-year-old African American female presented to the emergency department with a 24-hour history of a "burning rash" on her face. Three days before, she had received her first dose of messenger RNA (mRNA)1273 SARS-CoV-2 vaccine which was followed within hours by itching and redness of her chest, that resolved spontaneously before her facial eruption. Four days before, she had finished a 10-day course of oral norethindrone for secondary amenorrhea (her only recent novel medication)

Her allergies included diphenhydramine, penicillins, and onions (rash with the former two, anaphylaxis with the latter). Routine medications included ondansetron, bupropion, trazodone, lamotrigine, escitalopram, ibuprofen, and medroxyprogesterone. Physical examination revealed an afebrile morbidly obese woman with innumerable monomorphic nonfollicular pustules of the chin, upper cutaneous lip, and forehead (Figure 1). A punch biopsy from the left forehead showed neutrophilic pustular dermatosis (Figure 2) and bacterial culture of a lanced pustule was negative. Treatment was started with oral antihistamines and topical triamcinolone, and the eruption resolved within eleven days. The patient reported no recurrence after five months of follow-up. The patient did not receive a second dose of mRNA-1273 SARS-CoV-2 vaccine, and declined to undergo patch testing. 


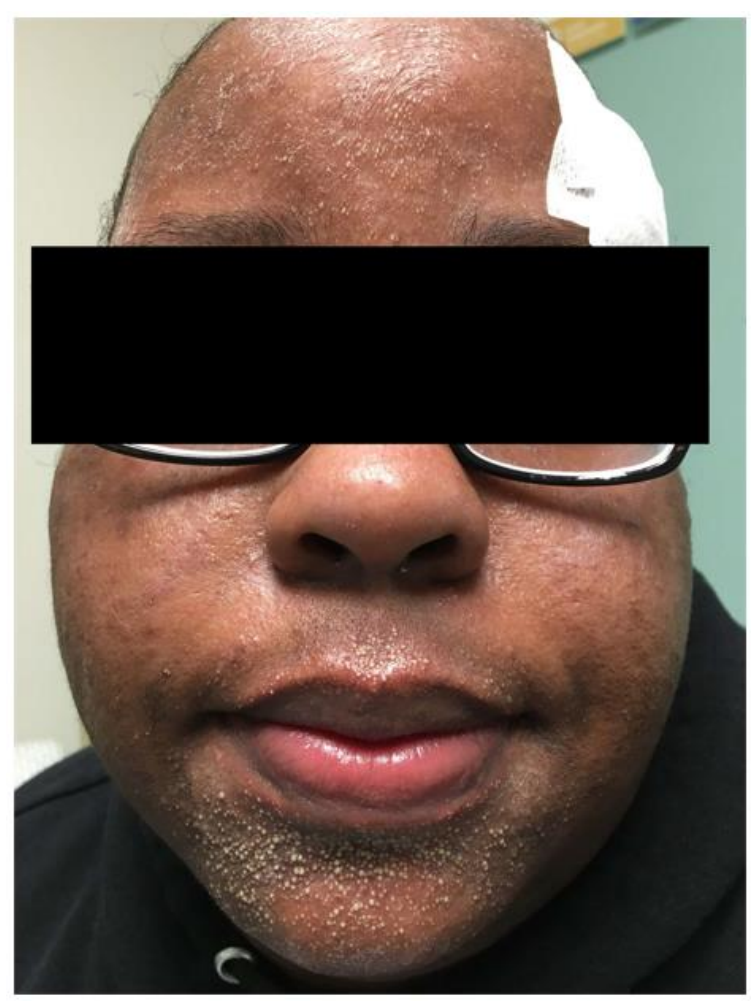

Figure 1: Innumerable monomorphic non-follicular pustules on the forehead, cutaneous lips, and chin.

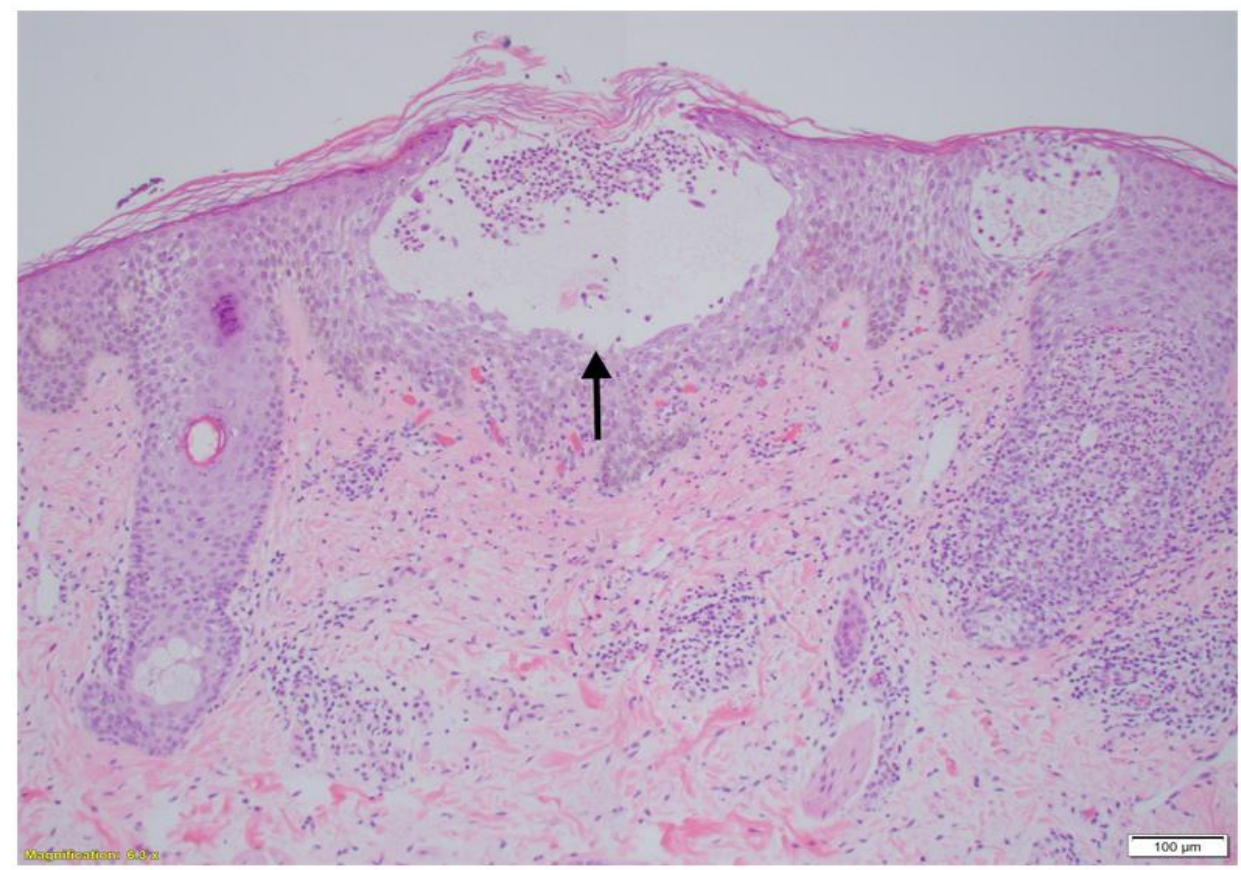

Figure 2: Histology showed subcorneal neutrophilic pustules (hematoxylin and eosin, original magnification 10x).

\section{Discussion}

The patient's ibuprofen and medroxyprogesterone acetate were unlikely culprits given her longstanding tolerance of these medications, and symptom onset began 4 days after discontinuance of her only novel medication (norethindrone). Thus we concluded the vaccine likely triggered her acute facial pustular eruption.

\section{Conclusion}

Vaccination with mRNA-1273 SARS-CoV-2 vaccine has been associated with acute facial pustular eruptions in two males over 50 and one female in her 20s. This eruption may occur after the $1^{\text {st }}$ or $2^{\text {nd }}$ dose of vaccine (even in the absence of adverse reactions to the $1^{\text {st }}$ dose). The reaction appears to be self-limiting but its differential diagnosis requires thorough 
evaluation to rule out other etiologies such infections or causative medications.

\section{References}

1. Villani A, et al. (2017). Acute Localized Exanthematous Pustulosis (ALEP): Review of Literature with Report of Case Caused by Amoxicillin-Clavulanic Acid. Dermatol Ther (Heidelb). 7:563-570.

2. Sidoroff A, et al. (2001). Acute generalized exanthematous pustulosis (AGEP) - a clinical reaction pattern. J Cutan Pathol. 28(3):113-119.
3. Kuno Y and Tsuji T. (1998). Acute Generalized Exanthematous Pustulosis upon Ingestion of a Progesterone Preparation. Acta Derm Venereol (Stokh). 78(5):383.

4. Ersoy S. (2004). Acute Generalized Exanthematous Pustulosis in Children. Arch Dermatol. 140(9):1172-1173.

5. Merrill ED, Kashem SW, Amerson EH, et al. (2021). Association of Facial Pustular Neutrophilic Eruption with Messenger RNA-1273 SARS-CoV-2 Vaccine. JAMA Dermatol. 157(9):1128-1130.
This work is licensed under Creative Commons Attribution 4.0 License

To Submit Your Article Click Here: Submit Manuscript

DOI: $10.31579 / 2690-4861 / 180$
Ready to submit your research? Choose Auctores and benefit from:

$>$ fast, convenient online submission

$>$ rigorous peer review by experienced research in your field

$>$ rapid publication on acceptance

$>$ authors retain copyrights

$>$ unique DOI for all articles

$>$ immediate, unrestricted online access

At Auctores, research is always in progress.

Learn more auctoresonline.org/journals/international-journal-of-clinicalcase-reports-and-reviews 